\title{
O lobo e o mago: uma leitura dos caminhos espirituais de Hermann Hesse a Paulo Coelho
}

Rafael Senra Coelho* Teresinha Vânia Zimbrão da Silva**

\section{Resumo}

Neste artigo, analisamos como o escritor brasileiro Paulo Coelho leu a ideia do aperfeiçoamento individual e da caminhada espiritual na obra do escritor alemão Hermann Hesse. Apesar da influência e de vários elementos em comum, Coelho soube promover a sua imagem, por meio de declarações e de estratégias de marketing bem conscientes. A contracultura dos anos 1960, ponto de partida para o projeto literário de Coelho, é em que converge a mais animada acolhida da obra de Hesse. A recepção crítica dos dois escritores no Brasil serve como suporte para a análise, além dos livros Demian, de Hesse, e $O$ Diário de um mago, de Coelho.

Palavras-chave: Literatura comparada. Teoria da recepção. Contracultura. Espiritualidade. Individualismo.
[Hesse] foi um escritor que me marcou muito.

Paulo Coelho

\section{Iniciando a jornada: considerações iniciais}

No presente artigo, analisamos como o escritor brasileiro Paulo Coelho encontrou influências seminais para suas obras no legado do escritor alemão Hermann Hesse, especificamente no que concerne à utilização estética do tema da caminhada espiritual e do desenvolvimento individual. Contudo, ainda que a biografia $O$ Mago, de Fernando Mo-

Doutorando em letras pela UFJF. Email: rararafaels@ yahoo.com.br

** Professora Associada da Graduação em Letras e da Pós-Graduação (Mestrado e Doutorado) em Letras: Estudos Literários. Pós-doutora. Email: teresinha. zimbrao@gmail.com

Data de submissão: mar. 2015 - Data de aceite: maio 2015

http://dx.doi.org/10.5335/rdes.v11i1.4541 
rais, ressalte a intensidade das leituras dos livros de Hesse, Coelho privilegiou menções a outros autores, construindo habilmente sua figura pública, segundo os rumos que pretendia dar à sua carreira. A forma como a crítica situava a carreira dos dois escritores serve como forte indicativo do duplo movimento que caracteriza, inicialmente, a influência de Hesse em Coelho, e, em seguida, as tentativas de Coelho de se vincular a outras tendências literárias.

A título de contextualização de ambos e de suas obras, iremos tecer nesse início de texto considerações mais gerais, para, no decorrer do texto, especificar o foco apenas nos livros Demian e $O$ Diário de um mago. Nessas obras, percebemos o passo inicial de ambos na ideia da caminhada individual e espiritual.

\section{O diário de um lobo e de um mago: legado dos autores}

Começemos pelas diferenças: emblemático escritor da literatura alemã, a posição de Hermann Hesse no panorama crítico é bem mais confortável que a de Paulo Coelho, que, por sua vez, talvez seja o escritor brasileiro mais hostilizado pela crítica especializada do país (algo justificável, à primeira vista, pela disparidade entre as altas vendagens de seus livros e o distanciamento que sua postura e sua estética promovem do cânone crítico e literário acadêmicos).
A outra diferença é cronológica, e aqui já assumimos a especificidade das obras que estudaremos: 23 anos separam a primeira publicação de Demian no Brasil, que ocorreu em 1964, pela editora carioca Cultura Brasileira (SOUZA, 2007, p. 293) da primeira publicação de $O$ Diário de um mago, pela editora Eco em 1987 (GONZAGA, 2007, p. 76). Tais datas são significativas a respeito da recepção, e comentaremos sobre isso a seguir.

Apesar de ter sido o primeiro livro ficcional de Coelho, O Diário de um mago não é seu primeiro livro. Em 1986, ele lançara Manual Prático do Vampirismo, co-escrito com Nélson Liano Jr., e, nessa publicação, ambos "contam como evocar vampiros e como afastá-los, além de algumas curiosidades sobre o tema" (GONZAGA, 2007, p. 79). Um ano depois, o autor publicou pela primeira vez um romance seu, sonho que nutria desde a adolescência, e $O$ Diário... vendeu 40 mil exemplares em menos de um ano (MORAIS, 2008, p. 60).

Percebemos nas duas obras que seus escritores deram um tratamento romanceado tanto a suas experiências quanto a suas projeções de vida, e tomaram o factual que lhes rodeava como matéria prima para sua ficção. Esses fatos nos permitem afirmar que, em algum nível, tais obras se inscrevem na categoria biográfica. De acordo com Philippe Lejeune, a autobiografia é uma "narrativa retrospectiva em prosa que uma pessoa real faz de sua própria existência, quan- 
do focaliza sua história individual, em particular a história de sua personalidade" (LEJEUNE, 2008, p. 14). Contudo, Lejeune distingue a autobiografia do romance biográfico; o segundo menos exato e mais complexo que o outro. Para o autor, nenhuma das duas formas se sobrepõe a outra, e ambas fazem parte do que ele chama de "espaço autobiográfico” (LEJEUNE, 2008, p. 43), campo metodológico no qual uma comunidade de leitores pode construir a autobiografia de um texto, não só pelos elementos compreendidos nele, mas também por outros textos e posicionamentos do autor em questão. Assim, o pacto autobiográfico é estendido, "sob forma indireta, ao conjunto de seus textos" (LEJEUNE, 2008, p. 43). Mais adiante, discutiremos esses aspectos biográficos percebidos nos romances de Hesse e Coelho.

Em ambos os livros, percebemos um divisor de águas. No caso de Coelho, além de ser seu primeiro livro de ficção, é também a inauguração de sua forma de escrever - sempre partindo do ponto de vista de um mago ou de uma bruxa, e que propaga a caminhada espiritual como algo comum e acessível a qualquer pessoa (aspecto conceitualizado por ele como bom combate). Da mesma forma, Demian representa um livro importante na carreira de Hesse, já que, além de ser o primeiro de sua trilogia mais importante (composta por Demian, Sidarta e O Lobo da Estepe), representa a entrada da terceira fase do escritor, atrelada ao expressionismo alemão.
Note-se que a bibliografia crítica em que nos apoiaremos para a análise de Hesse é de autores brasileiros, pois interessa-nos a recepção de Hesse no Brasil. Em um artigo intitulado Hermann Hesse e o expressionismo alemão, publicado em 1982, Antônio Espeshit afirma que Demian seria "a expressão máxima de todo o expressionismo germânico" (ESPESHIT, 1982, p. 2 apud SOUZA, 2007, p. 250). Até então esteticamente vinculado ao neo-romantismo, Hesse promove uma guinada literária em Demian que nortearia toda a sua carreira posterior, focalizando o desenvolvimento individual e a subjetividade como força positiva:

O arranque representado por Demian é, entretanto, mais significativo se se tem em conta seu valor de quebra-diques na própria contenção formal e emotiva da obra de Hesse. Até então, a despeito dos gritos convencionais de revolta contra a educação coercitiva do novecentismo germânico, representados por Peter Kamenzind (1904) e Unterm Rad (Debaixo das Rodas - 1906), seus escritos estratificam o burilar correto e neo-romântico de um mestre-escola provinciano, pontilhado de descrições de um gosto artífice, mas onde $o$ olhar se coloca numa posição alpina, de contemplação para baixo, paisagística.

É exatamente com Demian que o enfoque se modifica: a contemplação se volta para si mesma e vai buscar no interior do próprio personagem a visão multilatitudinal do mundo; a perspectiva se intromete na própria vivência autobiográfica e $\mathrm{o}$ autor ousa ser ele e proclamar sua mensagem (BARROSO In: HESSE, 1984, p. 4).

Para alguns autores, a tal trilogia de Hesse poderia ser interpretada como um único livro, apesar das diferenças dos nomes e lugares em que as histórias se passam. Os personagens Emil Sinclair, 
Sidarta e Harry Haller seriam, para alguns autores, a mesma pessoa, vista em momentos diferentes de sua caminhada pessoal. No artigo não assinado e intitulado De Demian às contas de vidro (publicado no Jornal do Brasil de 26 de maio de 1971), o autor comenta que, apesar da trama de Sidarta se passar no Oriente, seu enredo seria uma alegoria da revolta de Hesse com a casa dos pais, além do fato de que o personagem Harry Haller poderia ser considerado uma continuação de Sinclair (1971 apud SOUZA, 2007, p. 169). Ivo Barroso, um dos tradutores de Demian no Brasil, também analisa esse aspecto:

Demian, escrito em 1919, é o primeiro grande livro de Hermann Hesse no caminho que o conduz a Der Steppenwolf (O Lobo da Estepe) - sua indiscutível obra-prima de 1927 - e do qual Sidarta, que aparece em 1922, constitui a etapa intermediária. Pode-se dizer que o Harry Haller, de O Lobo da Estepe, é o Emil Sinclair, de Demian, na maturidade (BARROSO In: HESSE, 1984, p. 4).

Em Demian, mais que nos outros livros da trilogia, é perceptível o quanto seu autor permeia a narrativa com elementos de sua própria vida. Em um texto de 1957, Erwin Theodor conta que a primeira edição do livro não vinha estampada com o nome de Hesse, mas sim como se tivesse sido escrito por um tal "Emil Sinclair" (mesmo nome do protagonista), e até mesmo Thomas Mann teria escrito um ensaio indagando quem seria esse jovem e talentoso escritor (THEODOR, 1957 apud SOUZA, 2007, p. 128). Alguns anos antes, Hesse tinha escrito artigos e contos de caráter anti- -belicistas assinando como Emil Sinclair, e esses escritos inclusive chegaram a ser publicados no Brasil, reunidos em um livro chamado $O$ caderno de sinclair (ESTILL, 1987 apud SOUZA, 2007, p. 260). Percebe-se a intenção de Hesse em se associar com seu personagem, e, assim, evidenciar ainda mais o caráter semibiográfico do texto. Apesar de que Demian não deve ser encarado como uma biografia no sentido literal, e sim como uma ficção que se apropria de diversos elementos da vida real de Hesse. Um exemplo disso é encotrado em um artigo de 1979, intitulado Relinchando ao Vento, em que o autor Christopher Middleton conta que o personagem Pistorius teria sido baseado no psiquiatra junguiano J. B. Lang (MIDDLETON, 1979, p. 57 apud SOUZA, 2007, p. 225); e as ideias do suiço Carl Jung utilizadas pelo terapeuta teriam, como reitera Luiz Carlos Lisboa no texto A solidão de Hermann Hesse, influenciado a obra como um todo (LISBOA, 1984, p. 2 apud SOUZA, 2007, p. 258).

No caso do livro de Paulo Coelho, o autor deixa bem claro, em $O$ Diário de um mago, que é ele o narrador e o protagonista do livro, e, apesar do caráter por vezes mágico ou fantástico das situações descritas, afirma ter de fato vivenciado todos os eventos ali descritos. Na biografia $O$ Mago, Fernando Morais dedica o vigésimo terceiro capítulo a reconstruir a caminhada de Paulo pelo Caminho de Santiago, e por meio de sua escrita, reitera que o que Coelho descreve em seu romance teria realmente acontecido 
(MORAIS, 2008, p. 453). Na dissertação de mestrado intitulada Paulo Coelho em cena: a construção de um pop star, a autora Cláudia Assumpção Gonzaga não só afirma que $O$ Diário... é um livro autobiográfico (GONZAGA, 2007, p. 41), mas defende que o escritor procurou, sobretudo na fase inicial de sua carreira, vincular sua imagem com o arquétipo de um verdadeiro mago (GONZAGA, 2007, p. 76).

$\mathrm{O}$ recorte da narrativa em ambos os livros também apresenta um foco semelhante, pois os protagonistas autores se envolvem em tramas nas quais o desembocar dos eventos, o leitmotiv da história, é o desenvolvimento pessoal e espiritual. A revolução não só parte de ações individuais, mas também tem como alvo o próprio indivíduo em seu processo subjetivo. Assim, por meio do cumprimento de uma série de tarefas e etapas, esses dois alter egos dos escritores buscam burilar e aperfeiçoar seu ser, sua interioridade.

Esse tipo de proposta estética de ambos, que elege o individualismo ativo e a liberdade de pensamento, teve seu auge nos anos 1960. A princípio, voltar nossa atenção para essa época parece um contrasenso, já que em 1962, falecia na Suiça um octogenário Hesse, enquanto Coelho ainda era um jovem aluno ginasial do colégio Santo Inácio, no Rio de Janeiro (MORAIS, 2008, p. 105). Entretanto, ainda que pertencessem a gerações diferentes, o contexto cultural daquela década é fator imprescindível para se entender um importante ponto de convergência entre suas obras.

A geração de jovens nascidos após a segunda guerra mundial, chamada de baby boom, foi quem consolidou, nos anos 1960, um movimento de contestação social que seria batizado como contracultura. Nessa lógica, agregava-se tudo que parecesse contestar o modo de vida da civilização ocidental, desde o rock'n roll e as filosofias orientais à literatura beatnik e o amor-livre. Novas propostas para a vida e novas utopias eram a pauta das ações da juventude, como explica Luiz Carlos Maciel:

[...] Os meninos daquela geração tiveram aquela intuição. Por quê? De onde ela caiu na cabeça deles, no espírito deles? De onde veio? Ninguém sabe. Aconteceu simplesmente. [...] Nós queríamos que a nossa vida fosse diferente da vida que a gente via os adultos viverem. O que a gente via no nosso estilo de vida, no Ocidente, desde aquela época? Doença, neurose, crime, tudo que a gente tem de ruim. A característica da sociedade era a multiplicação de instituições, tipo hospital, porque todo mundo era doente; prisão, porque todo mundo era criminoso; por aí (MACIEL In: ALMEIDA, NAVES, 2007, p. 66).

Parece ter havido uma afinidade e uma identificação entre os anseios dessa geração e os valores propagados pelos livros de Hesse da sua fase pós-romântica. Assim, resgatado por um vasto contingente de leitores nos anos 1960 e 1970 , o escritor alemão pareceu mais atual do que nunca naquelas décadas. De acordo com Christl Brink, "a segunda fase do prestígio de Hesse começou após a sua morte em 1962, sendo talvez influenciada pela euforia com que os norte-americanos aceitavam a obra do autor nos anos entre 
sessenta e setenta" (BRINK, 1980, p. 11 apud SOUZA, 2007, p. 20).

Em um texto não assinado, publicado na edição do jornal $O$ Globo em dezembro de 1977, afirma-se que ao ser "redescoberto, na década de 1960, pelos sonhos de uma nova cultura e pelo clima de mutação e liberdade [...], Hesse passou a ser reverenciado como profeta de uma geração, ao lado de escritores beatniks e artistas de vanguardas" (apud SOUZA, 2007, p. 222-223). Aparentemente, a postura que Hesse assumiu em suas obras a partir de Demian acabou por antecipar uma série de elementos estéticos do que viria a se tornar a contracultura dos anos 1960. Basta dizer que a música que se tornou hino dessa geração, Born to be wild (trilha sonora do emblemático filme Easy Rider) foi composta e interpretada por um grupo chamado Steppenwolf, não por acaso, o mesmo nome do mais famoso livro de Hesse (BORBÉLY, 2006, p. 15).

Diversos episódios da vida de Paulo Coelho são representativos do estilo de vida da contracultura. Não só morou no Solar da Fossa, endereço típico de hippies e rebeldes da época (MORAIS, 2008, p. 221), e conheceu pessoalmente os integrantes do grupo de teatro americano The Living Theatre (MORAIS, 2008, p. 235), mas também viajou pelos Estados Unidos como um hippie, pedindo carona e seguindo os rastros de um de seus escritores favoritos, o peruano Carlos Castañeda, considerado um dos gurus da contracultura (MORAIS, 2008, p. 247).
Esses exemplos, retirados da biografia do autor, ajudam a entender a recepção que ele teve de seu contexto histórico, e como isso o influenciou em sua literatura. Parece-nos oportuno discutir tais dados biográficos, sobretudo, pelo fato de o livro $O$ Diário de um mago ser fortemente inspirado na própria vida do escritor.

Entretanto, é possível perceber que ao longo de sua carreira, houve uma intenção de Coelho de se afastar dos temas místicos. Até mesmo a figura do "mago", tão característica de sua imagem pública nos anos 1980 e na primeira metade dos anos 1990, foi deixada de lado. Para Cláudia Gonzaga, esse processo de recriação de sua persona pública se deu na segunda metade dos anos 1990, e culminou não só na revisão de sua recepção pela crítica, mas em seu ingresso na Academia Brasileira de Letras (GONZAGA, 2007, p. 86). Assim, o homem que um dia foi chamado de "Castañeda de copacabana” (MORAIS, 2008, p. 472) passou a citar como suas maiores influências escritores como William Blake, Jorge Luis Borges e Henry Miller (COELHO, 2001). De acordo com Gonzaga,

[...] a vontade de ser visto como um escritor e não mais como um mago fez com que Paulo Coelho começasse a citar nomes de escritores consagrados em suas entrevistas, mostrando, assim, que possui conhecimento do assunto. Além de cada vez mais, frequentar ambientes literários (GONZAGA, 2007, p. 87).

Aqui podemos entender porque Coelho trataria de desbancar Hermann 
Hesse em uma entrevista dada à revista Veja, uma das mais lidas no país. O escritor cita então Sidarta, de Hesse, como um livro "mal acabado": "Mesmo um livro como Sidarta, do Hermann Hesse, é uma coisa mal-acabada. O cara não soube acabar o livro, entendeu? Termina com aquela frase: "Tem que olhar o rio". Que rio, pô? Acho que o Hermann Hesse não sabia como terminar o livro e meteu essa história aí de rio" (COELHO, 2001).

A entrevistadora tenta argumentar que Hesse foi um ganhador do prêmio Nobel de literatura, ao que Coelho responde que "Sim, mas eu tenho direito de dizer isso sobre ele, até porque foi um escritor que me marcou muito. $\mathrm{O}$ fato de Sidarta acabar mal não invalida o resto do livro" (COELHO, 2001).

O comentário desdenhoso sobre o escritor alemão certamente não surgiu de modo aleatório na resposta de Coelho. Afinal, diversos críticos e resenhistas já associaram as obras e a recepção de ambos, devido ao interesse comum pelo misticismo. Esse elemento, que surge nos livros de Hesse e Coelho logo após os livros analisados nesse artigo, é quase sempre citado (principalmente no caso do brasileiro) de maneira pejorativa, e vinculado temáticamente com o gênero literário da autoajuda. Como em uma crítica feita dois anos antes da entrevista de Coelho à Veja, em que, no artigo intitulado $O$ eterno retorno do alemão que amava a indisciplina, Carlos Haag compara os dois escritores:
Se o escritor alemão (naturalizado suíço) Hermann Hesse desconfiasse que, um dia, toda uma geração o leria como se fosse um Paulo Coelho teutônico, com certeza teria pedido que seus livros fossem queimados em praça pública pelos nazistas. Tudo bem, a uma primeira vista, a sua obra, que definiu como sendo, do primeiro ao ultimo escrito, uma defesa - até mesmo um SOS, para usar palavras suas - da personalidade, do ser individual, parece ocultar aquela bata de algodão indiano - se falarmos em Sidarta, então, a coisa fica ainda mais tendenciosa - e um pezinho na tal auto-ajuda literária [...] Mas não se engane [...] Hesse foi um digno representante da literatura do século 20 , um defensor da volta ao mundo clássico, em oposição a um mundo que cria mergulhado na vulgaridade folhetinesca (HAAG, 1999 apud SOUZA, 2007, p. 35).

Nesse artigo, publicado no jornal $O$ Estado de São Paulo, Haag cita Paulo Coelho como exemplo de literatura de autoajuda, tentando distanciar Hesse desse nicho específico. Para o crítico, “ele não foi um guru da contracultura, mas um bom literato [...]. O temerário foi a posteridade jovem pensar ter reconhecido nele um manual" (HAAG, 1999 apud SOUZA, 2007, p. 35). O que Haag considera temerário na recepção de Hesse pelos jovens na década de 1960 deve ter sido algo talvez desejável por Coelho no primeiro momento de sua carreira (que Gonzaga define como aquele em que a imagem do mago se sobrepunha à do escritor) já que, além de se portar como um verdadeiro guru, escreveu pelo menos dois livros intitulados como manuais (o já citado $O$ manual prático do vampirismo, em 1986, e $O$ manual do guerreiro da luz, em 1997). 
A projeção da imagem que Paulo Coelho trabalhou a partir da segunda metade dos anos 1990 fica evidente quando afirmações como "mas não há outra definição para mim: sou um mago" (GONZAGA, 2007, p. 74) dão lugar à declarações como "sou antes de tudo um escritor" (GONZAGA, 2007, p. 83). Essa intencional guinada em sua persona pública acompanhou também sua produção literária, o que possivelmente explica porque Coelho não queira ser associado a Hesse. Contudo, como mostra a citação da entrevista dada à revista Veja, fez a ressalva de assumir que o alemão o marcou muito, e tal fato é corroborado por Fernando Morais na biografia $O$ Mago.

Morais teve acesso ao baú em que Paulo Coelho guardou não só anotações pessoais em 170 cadernos, mas $94 \mathrm{CDs}$ de gravações, feitas entre 1959 (quando o escritor tinha apenas doze anos) até 1995 (MORAIS, 2008, p. 88). O acervo contido nesse baú é como um diário de Coelho, e um dos mais constantes hábitos ali registrados era o de escrever resenhas e dar notas a obras literárias. Morais afirma que o futuro escritor de sucesso era um leitor voraz, que "desde que iniciara a anotação sistemática de suas leituras, quatro anos antes, lera mais de trezentos livros, ou 75 por ano - número estratosférico considerando-se que cada brasileiro lia em média, na época, um único livro por ano" (MORAIS, 2008, p. 246). Nessa mesma época, fora capaz de ler e avaliar todos os livros de Hermann Hesse publicados no Brasil com a nota máxima de seu critério (mesma nota que dera, no mesmo período, aos seus ditos influenciadores Henry Miller e Borges):

Lia, fazia um pequeno comentário sobre cada obra e, como os críticos literários que tanto o infernizariam, distribuía estrelas a seu bel-prazer. Receber quatro estrelas, a mais alta cotação, era privilégio de poucos, como Henry Miller, Borges e Hemingway. [...] Nesse período lera, comentara e atribuíra estrelas a todos os seis livros publicados no Brasil pelo alemão Hermann Hesse (inclusive, claro, O Jogo das Contas de Vidro, Prêmio Nobel de Literatura de 1946) (MORAIS, 2008, p. 247).

Esse trecho corrobora a premissa do artigo, uma vez que Coelho dera tanto valor a Hesse em suas avaliações de livros quanto dera aos seus favoritos, como Castañeda, Borges ou Miller. A forma como Paulo Coelho se projeta no início de sua carreira e sua ligação com a contracultura dizem muito sobre como o escritor foi lido nessa primeira fase.

\section{Jornadas espelhadas: comparação das obras e autores}

Voltando aos pontos discutidos no início, tanto Demian quanto O Diário de um mago apresentam elementos autobiográficos. Talvez a semelhança estrutural mais notável nos dois livros seja a dinâmica entre os personagens: um protagonista que passa por uma jornada existencial e espiritual, e para realizá-la conta com a ajuda de um guia ou mestre. De Jesus Cristo a Buda, o 
tema de um guru ou orientador e seu(s) protegido(s) é comum em tradições religiosas e espirituais de todo o mundo.

Em Demian, esse mestre é citado já no título da obra, e a todo momento o personagem Sinclair tem sua atenção voltada para ele. Pode-se dizer que o livro é construído não só na caminhada individual de Sinclair, que envolve a elaboração gradual de sua percepção de mundo (e que vincula o romance à tradição alemã do bildungsroman, tão comum a obras de Hesse ou de seu contemporâneo Mann), mas na relação que se estabelece entre ele e Demian. Tudo o mais é secundário, seja a própria família de Sinclair, a universidade, os outros amigos ou mestres "temporários" (como Pistorius), e mesmo as paixões. Uma outra camada relevante só surge quando aparece a mãe de Demian, tratada como uma verdadeira encarnação do feminino ancestral e fundamental (não por acaso, a personagem se chama Eva).

Em O Diário de um mago, contudo, a relação entre Coelho e Petrus (seu mestre na ordem RAM) possui um grau de importância menor dentro da trama como um todo. Ela não se desenvolve tanto no nível pessoal, mas sim no aumento gradativo de dificuldade das tarefas pelas quais Coelho passa. O foco da trama nunca se desvia do personagem-autor, em sua jornada rumo à espada que fará dele um mago. Assim, percebemos que, nesse caso, a figura do mestre não é tão fundamental para o entendimento dos eventos como em Demian, e que somente faz a ponte entre Coelho e a desejada espada.
Outro ponto curioso trata do modo como os protagonistas-autores se posicionam nos eventos em que estão inseridos. Sinclair/Hesse é um completo deslocado, que não encontra um lugar confortável nem no seio familiar, e muito menos na sociedade ou nas instituições. Sua busca é quase sempre angustiada e solitária. Já Coelho é uma pessoa plenamente integrada ao sistema, bem sucedida, que logo ao chegar à Espanha para iniciar sua importante caminhada espiritual, se vê enormemente preocupado sobre seus negócios no Brasil (COELHO, p. 8). Percebemos que essas duas formas de tratar os protagonistas refletem muito da vida dos autores no momento de concepção das respectivas obras.

Quando Demian foi escrito, Hesse havia deixado sua Alemanha natal para morar na Suiça, e apesar de viver em um país neutro, o desenrolar da Primeira Guerra Mundial lhe causou efeitos nefastos. O sentimento de impotência ante a irracionalidade daquele contexto levou o escritor a um parcial esgotamento nervoso, e só obteve certo alento ao se tratar com o psicanalista J.B.Lang (MIDDLETON, 1979, p. 57 apud SOUZA, 2007, p. 225). Lang não só teria provavelmente divulgado as ideias de Jung à Hesse, como também compartilhado um tratado do psicanalista intitulado Sete Sermões aos Mortos, que continha menções ao deus Abraxas muito semelhantes às utilizadas em Demian (HOELLER, 1991, p. 44).

Nessa época, Hesse empreendia uma busca espiritual que não privilegiava $o$ cristianismo católico e protestante, e abar- 
cava elementos de outras fontes, como a gnose. As interpretações de Demian sobre determinadas narrativas bíblicas questionavam a visão cristã sobre o bem e o mal. Se para Sinclair/Hesse era tarefa difícil se afastar do cristianismo, de outro modo isso não significava - como para a maior parte de seus contemporâneos - um afastamento de qualquer caminho espiritual.

A forma como Paulo Coelho aborda a espiritualidade é diametralmente oposta à essa. No prefácio do livro Por que Paulo Coelho teve sucesso, de Mário José Maestri Filho, o professor José Gaston Hilgert compara a visão tradicional acerca dos magos e bruxos com o tratamento que Paulo Coelho dá a essas figuras. É irônico como Coelho se proclama como um mago, ser historicamente herético, e ao mesmo tempo se entrega ao cristianismo papal e seus ritos.

Bruxos, mágicos, feiticeiras e alienação social são os grandes caracteres da obra coelhiana. Seus feiticeiros não são como os da Idade Média: "envelhecidos", "angustiados com a morte", subversivos, hetedoroxos e associais [...], em ruptura com a ideologia e o credo católicos [sic] romanos das elites feudais, realizando práticas abominadas pela Igreja ou inquirindo o mundo racional com objetivos racionalistas". Os bruxos de Paulo Coelho "são profissionais de sucesso, sedutores, modernos". "Moram em residências elegantes e viajam pelo mundo despreocupados com os gastos". [...] Em resumo, os magos de Coelho apresentam-se "conformistas e socialmente integrados ao mundo capitalista, adeptos levemente heterodoxos do cristianismo papal" (HILGERT In: MAESTRI, 1999, p. 16).

Diferente de abordagens da caminhada espiritual feitos por escritores em outras épocas, Paulo Coelho assume a pro- posta de tornar possível que essa jornada possa ser iniciada por qualquer pessoa e em qualquer circunstância. Apesar de ele próprio ter percorrido o Caminho de Santiago seguindo os preceitos da ordem RAM, Coelho deixa claro, logo no início do livro, que não há necessidade nem de uma ordem secreta nem de um mestre para que as pessoas empreendam sua busca pessoal (COELHO, p. 2). Gonzaga comenta como o escritor trabalhou sua imagem dentro e fora dos livros, mesclando a figura de um mago com a de uma pessoa comum, com a qual muitos leitores podem se identificar. Desse modo, a jornada espiritual na perspectiva coelhiana se assume como um fenômeno ao mesmo tempo comum e extraordinário:

Entretanto, era preciso aproximar-se dos leitores, do público. Era preciso um pé na magia e outro na realidade, para que a imagem de Paulo Coelho, além de extraordinária, fosse comum. Afinal, o autor pregava que qualquer um poderia ser um mago, logo, um mago também poderia ser uma pessoa como qualquer outra, para assim, tornar-se familiar a seus seguidores (GONZAGA, 2007, p. 77).

Percebemos aqui um importante paradoxo entre os dois escritores: de um lado, Hermann Hesse, com sua defesa do individualismo e sua suspeita das instituições estabelecidas, e que, apesar disso, obteve amplo reconhecimento crítico de sua obra. De outro, Paulo Coelho, que depois de se lançar publicamente como um "mago", se declarou cristão e se tornou um membro da Academia Brasileira de Letras. Contudo, sua obra continua sendo menosprezada pela academia e por grande parte dos críticos literários. 
Essa distinção abre espaço para discutirmos como cada um dos autores elabora a questão do mal em seus livros. Uma melhor compreensão desse aspecto é crucial para que possamos entender como se desenvolve a caminhada espiritual desses personagens/autores.

Em Hesse, percebemos uma influência de Jung e da gnose na forma aparentemente adequada de como o mal deve ser abordado. A ótica do personagem Demian gira em torno da integração do mal pelo bem, em detrimento da negação desse mal praticada sobretudo pelo cristianismo católico:

Esse Deus da antiga e da nova Aliança é, antes de tudo, uma figura extraordinária, mas não o que realmente deveria ser. Representa o bom, o nobre, o paternal, o belo e também o elevado e o sentimental... está bem! Mas o mundo se compõe também de outras coisas. $\mathrm{E}$ todas essas coisas são simplesmente atribuídas ao Diabo; toda essa parte do mundo, toda essa outra metade é encoberta e silenciada. Glorifica-se a Deus como o Pai de toda a vida, ao mesmo tempo em que se oculta e se silencia a vida sexual, fonte e substrato da própria vida, declarando-a pecado e obra do Demônio. Não faço a menor objeção a que se adore esse Deus Jeová. Mas creio que devemos adorar e santificar o mundo inteiro em sua plenitude total e não apenas essa metade oficial, artificialmente dissociada. Portanto, ao lado do culto de Deus devíamos celebrar o culto do Demônio. Isto seria o certo. Ou mesmo criar um deus que integrasse em si também o demônio e diante do qual não tivéssemos que cerrar os olhos para não ver as coisas mais naturais do mundo (HESSE, 1984, p. 56 -57).

Declarações como essas preparam o terreno para que, mais adiante na trama, Demian cite o deus Abraxas, en- tidade da gnose que cumpre o propósito ontológico de unir o mal e o bem. Jung afirma que

[...] preferimos, por conseguinte, localizar o mal nos indivíduos criminosos ou grupos de criminosos, enquanto lavamos as mãos na inocência e ignoramos a inclinação geral do mal (JUNG, 1961, p. 115).

$\mathrm{Na}$ teoria junguiana, essa união de opostos acontece pela integração consciente da sombra, parte da psique do indivíduo constituída por seus recalques e repressões.

A presença do mal em $O$ Diário de um mago é simbolicamente tratada como um demônio. Porém, diferentemente de Abraxas em Demian, essa entidade não deve ser integrada, mas sim combatida. O demônio aparece diversas vezes para Coelho na narrativa, primeiro como um cigano embusteiro, e depois como um cão (COELHO, p. 54). É nessa forma de cachorro que Coelho o enfrenta (COELHO, p. 76), e tal ato revela-se como uma tarefa necessária para que o protagonista-autor possa enfim encontrar sua espada (COELHO, p. 80).

\section{Fim da jornada: conclusão}

Ainda que Coelho busque imprimir em seu estilo uma gama de elementos próprios, percebemos que seu romance guarda uma relação de influência com a ideia estética do desenvolvimento individual como proposta literariamente por Hesse. A perspectiva que oscila entre biográfica e ficcional é detectada na obra de ambos. Contudo, Coelho - um 
escritor que emerge em meio a um contexto da cultura de massa e de suportes midiáticos - se mostrou mais consciente de alguns artifícios de autopromoção e projeção de uma imagem, primeiro como mago e, depois, como escritor.

Por meio da visão de mundo que parte de uma linguagem pessoal, os livros desses escritores tentam traduzir, no âmbito literário, suas buscas pessoais por autoconhecimento e espiritualidade. Coelho leu Hesse e reproduziu num outro contexto o tema da caminhada espiritual.

\section{The wolf and the wizard: the} spiritual journey from Hermann Hesse to Paulo Coelho

\section{Abstract}

In this article, we analyse the reading by Paulo Coelho of the literary theme of spiritual journey in Herman Hesse. Despite the influence and several elements in common, Coelho knew promote his image through declarations and self-conscious marketing strategies. The 60's counterculture was the starting point for Coelho's literary project, and is where converge the most liveable accepted to the work of Hesse. This essay proposes a study about individual improvement and spiritual journey, in articulation with the reception in Brazil of the books Demian, written by Hermann Hesse, and $O$ Diário de um mago written by Paulo Coelho.

Keywords: Comparative literature. Reception theory. Counterculture. Spirituality. Individualism.

\section{Referências}

BORBÉLY, Stefan. Hermann Hesse's spiritual formula. Iasi: Philologica Jassyensia Journal, year 2, n. 1, 2006.

COELHO, Paulo. Chega de mágica. Entrevista concedida a Thaís Oyama. In: Revista Veja. Edição 1.714, de 22 de agosto de 2001. Disponível em http://veja.abril.com.br/220801/ entrevista.html.. Acesso em: 03 maio. 2012

COELHO, Paulo. O diário de um mago. Edição especial digital disponibilizada na página oficial www.paulocoelho.com.br. Acesso em: 04 set. 2008.104 p.

GONZAGA, Cláudia Assumpção. Paulo Coelho em cena: a construção do escritor pop star. 2007. 105f. Dissertação (Mestrado em Letras) - Centro de Teologia e Ciências Humanas, Pontifícia Universidade Católica do Rio de Janeiro, Rio de Janeiro, 2007.

HESSE, Hermann. Demian. Rio de Janeiro: Record, 1984. 145p.

HILGERT, José Gaston. Despindo a capa do bruxo. In: MAESTRI, Mário José. Por que Paulo Coelho teve sucesso. Porto Alegre: Editora AGE, 1999. p. 13-18.

HOELLER, Stephan A. A gnose de Jung e os sete sermões aos mortos. São Paulo: Cultrix, 1991. 309p.

JUNG, C.G. Memórias, sonhos e reflexões. Rio de Janeiro: Nova Fronteira, 1986. 150p.

JUNG, C.G. O eu desconhecido. Rio de Janeiro: Fundo de Cultura, 1961. 136p.

LEJEUNE, Philippe. O pacto autobiográfi$c o$ : de Rousseau à internet. Belo Horizonte: Editora UFMG, 2008. 404p.

MACIEL, Luiz Carlos. O tao da contracultura. In: ALMEIDA, Maria Isabel Mendes de. NAVES, Santuza Cambraia (Org.). "Por que não"?: rupturas e continuidades da contracultura. 7Letras, 2007. p. 64-75. 
MORAIS, Fernando. O mago. São Paulo: Planeta, 2008. 630p.

SOUZA, João Paulo Francisco de. Um lobo nos trópicos: a recepção crítica de Hermann Hesse no Brasil. 2007. 297f. Dissertação (Mestrado em Letras) - Faculdade de Ciências e Letras de Assis, Universidade Estadual Paulista "Júlio de Mesquita Filho", São Paulo, 2007. 297 p. 